\title{
GEOMETRICAL STRUCTURE OF LEAD NUCLEI AND OF SOME OTHER CHEMICAL ELEMENTS
}

\author{
Yu. A. Aminov \\ Mathematical Division, B. Verkin Institute for Low Temperature \\ Physics and Engineering of the National Academy of Sciences of Ukraine, 47 Nauka ave., 64103 Kharkiv, Ukraine
}

(Received March 20, 2020)

\begin{abstract}
The interior structure of nucleus of the chemical element lead is given in the form of shell sequence of polyhedrons. This sequence represented with the help of some arithmetic progression of positive numbers, which connects with hypothesis of $\alpha$-particles synthesis of nuclei. Other chemical elements also are considering with this point of view. On the graph of abundance of chemical elements in Solar system picks correspond to these elements. In the work the Table of numbers of nucleons in nuclei of these elements is proposed and we obtain combinatoric type of polyhedrons, which considering as shells of these chemical elements.
\end{abstract}

PACS: $21.60-\mathrm{n}, 21.45 .+\mathrm{v}, 98.80 . \mathrm{ft}$

\section{INTRODUCTION}

The chemical element lead is remarkable element thanks to that its isotopes finish three radioactive rows under $\alpha$-decay with numbers $4 n, 4 n+2,4 n+3$ of nucleons in nuclei, see [1]

$$
\begin{gathered}
T h^{232}=P b^{208}+6 H e^{4} \rightarrow 4 n, \\
U^{235}=P b^{207}+7 H e^{4} \rightarrow 4 n+3, \\
U^{238}=P b^{206}+8 H e^{4} \rightarrow 4 n+2 .
\end{gathered}
$$

The forth radioactive row which corresponds to numbers $4 n+1$ does not exist at Nature, because was consist from elements with short time of life, except bismuth $B i^{209}$.

Writing expressions have only symbolic sense because the equality of right and left parts has place only for numbers of nucleons, but does not correct for protons. Correct notation must be following

$$
\begin{gathered}
T h_{90}^{232}=P b_{82}^{208}+4 H e^{4}+8 n \\
U_{92}^{235}=P b_{82}^{207}+5 H e^{4}+8 n \\
U_{92}^{238}=P b_{82}^{206}+5 H e^{4}+12 n .
\end{gathered}
$$

It is interesting question: what is the property of lead (Plumbum) isotopes nuclei due which the radioactive decay finished? By this cause in literature one writes that the nucleus $P b^{208}$ is two-times magic: 82 protons and 126 neutrons. But it is not explanation. It is pertinent to put the question: why natural radioactivity exists?
Here remember the words of M.Curie at her book "Radioactivité" [2] that the cause of atomic decay can be at intrinsic structure or on the influence of exterior factors. One supposed that such exterior factor could be some ultra penetrate rays with source in cosmic space or inside earth (Pierre Curie, M.Curie, J.Perren).

Also, why the radioactivity of radium is more stronger than of uranium ?

E.Rezerford in his lecture "Some cosmical aspects of radioactivity" [3] pointed to that illumination of radium is almost at 2 millions times larger than activity of uranium.

\section{INTRINSIC STRUCTURE OF NUCLEUS $P b^{208}$}

Consider the intrinsic structure of nucleus $P b^{208}$ under supposition that it synthesis was with the help of $\alpha$-particles which consequently were united at shells. Early at the work [4] we proposed the following composition for nuclei $A r^{36}, C a^{40}, F e^{56}$

$$
\begin{gathered}
(2+3+4) 4=36 \rightarrow A r^{36}, \quad(2+3+5) 4=40 \rightarrow C a^{40}, \\
(2+3+4+5) 4=56 \rightarrow F e^{56},
\end{gathered}
$$

Writing above expressions correspond to shell structure of nuclei.Representatively, that these elements due the graph of abundance of the elements in the Solar system have larger abundance between close to them by atomic weight. Similar expansions we write for other light elements and for few heavy nuclei. And it interesting to remark that for correspondent heavy nuclei the graph of the abundance also has peaks. This approach we use now under consideration of $\mathrm{Pb}^{208}$.

\footnotetext{
*Corresponding author E-mail address: aminov@ilt.kharkov.ua
} 
It has place

$$
(3+4+5+6+7+8+9+10) 4=208 \rightarrow P b^{208},
$$

To every number $m$ in brackets some shell corresponds at the form of Polyhedron with $4 \mathrm{~m}$ vertexes. This polyhedron is been constructed by $m$ $\alpha$-particles. Every such shell is closed, that means, that every such shell can not be complemented by other nucleons. Because such shell are completed, so nucleons in it are strongly connected. At thorium $T h^{232}$ nucleus the six $\alpha$-particles are outside of external shell of $P b^{208}$ and they do not make next complete shell. Therefore these $\alpha$-articles can separate from the nucleus.

Remark that for the polyhedrons at the construction the following condition has place: if $S$ is its the surface area and $V$ is the volume then the fraction

$$
\frac{S^{3}}{V^{2}}
$$

has minimal value between polyhedrons with same combinator kind. At our work [4] chapter 6 we connected this question with half empirical H.BetheC.F.Weizsä cker formula for nuclear energy.

Consider nuclei of $P b^{207}$ and $P b^{206}$. Its numbers of nucleons differ of $P b^{208}$ on 1 and 2 respectively. We suppose that the construction of these nuclei is almost same as $P b^{208}$, but from some shell $P b^{208} 1$ or 2 nucleons are derived respectively. This receding does not affect strongly on the stability of the nucleus.

Remark that on the graph of abundance of chemical elements $P b^{208}$ has considerably more larger abundance than close to it elements and has more larger relative abundance than $P b^{207}, P^{206}, P^{204}$.

The expression (1) can be at concordance with experimental dates about division of uranium nucleus $U^{235}$ by slow neutron. It is known the following schema of division, which was obtained at the experiments, see.[1], chapter 12

$$
U_{92}^{235}+1 n \rightarrow L a_{57}^{147}+B r_{35}^{87}+2 n .
$$

Here $n$ denotes a neutron. It is interesting to consider intrinsic structure of elements which obtained as result of division. We have for the nucleus bromine $\mathrm{Br}^{87}$

$$
(4+5+6+7) 4-1=87 .
$$

Similar expression has place for lanthanum $L n^{147}$

$$
(3+8+9+10) 4+7 \times 4-1=147 \text {. }
$$

We see from (3), (4) that the products of the division are composed from same shells as $U^{235}$.

It is surprising ! Probably the neutron of division beat out the core of uranium in the form $\mathrm{Br}^{87}$. Because the shells are not solid bodies, so it possible for this part to go out and the division of nucleus $U^{235}$ in the space on two parts.
Remark, that in the nucleus of $\mathrm{Pb}^{208}$ at the shells with $3,4,5,6$ and $7 \alpha$-particles contain 35 protons and at the rest part 47 .

Similar picture has place under the second version of the division

$$
U_{92}^{235}+1 n \rightarrow B a_{56}^{140}+K r_{36}^{93}+3 n .
$$

In this case it is possible to propose the following division

$$
\begin{gathered}
K r_{36}^{93}:(1+4+5+6+7) 4+1=93 \\
B a_{56}^{140}:(1+8+9+10) 4+7 \times 4=140 .
\end{gathered}
$$

Consider the structure of radium nucleus, which belongs to radioactive row begin from $U^{238}$. We can write

$$
R a_{88}^{226}=P b_{82}^{206}+3 H e^{4}+8 n .
$$

We see,that the exterior shell of radium more scarcity to closed shell than the uranium $U^{238}$. Hence it radioactivity is more larger.

\section{SOME ANOTHER CHEMICAL ELEMENTS}

Write the list of some chemical elements with heavy nuclei and their conjectural compositions. Let us to go along peaks of the abundance graph

$N i^{60} \rightarrow(1+2+3+4+5) 4=60$, -nickel

$Z n^{64}, C u^{64} \rightarrow(1+2+3+4+5) 4+4=64$,- zinc and copper

$G e^{72} \rightarrow(3+4+5+6) 4=72,-$ germanium

$S e^{80} \rightarrow(2+3+4+5+6) 4=80$,- selenium

$K r^{84} \rightarrow(1+2+3+4+5+6) 4=84,-$ krypton

$\mathrm{Sr}^{88} \rightarrow(4+5+6+7) 4=88,-$ strontium

$Z r^{90} \rightarrow(4+5+6+7) 4+2=90$,- zirconium

$R u^{102} \rightarrow(3+4+5+6+7) 4+2=102,-$ ruthenium

$S n^{120} \rightarrow(4+5+6+7+8) 4=120,-$ tin

$T e^{128} \rightarrow(2+4+5+6+7+8) 4=128$,- technetium

$X e^{132} \rightarrow(3+4+5+6+7+8) 4=132,-$ xenon

$B a^{138} \rightarrow(2+3+4+5+6+7+8) 4-2=138,-$ barium

$C e^{140} \rightarrow(2+3+4+5+6+7+8) 4=140$,-cerium

$G d^{156} \rightarrow(4+5+6+7+8+9) 4=156$,-gadolinium

$P t^{196} \rightarrow(4+5+6+7+8+9+10) 4=196,-$ platinum

$A u^{197} \rightarrow(4+5+6+7+8+9+10) 4+1=197,-$ gold

$P b^{208} \rightarrow(3+4+5+6+7+8+9+10) 4=208,-$ lead

$P u^{244} \rightarrow(3+4+5+6+7+8+9+10) 4+9 \times 4=244 .-$ plutonium.

The graph of abundance of the chemical elements has peaks on majority of this set of elements, see the Table III from [6]. It shows that their lager abundance at comparison with close elements connected with complete filling of their shells by $\alpha$-particles. 
Last writing element- plutonium has very small abundance and its exterior shell is not completed.

\section{TWO TABLES}

After my report on the seminar in my institute
FTINT my colleague Vasiliy Gorkaviy prepare the following Table (Table 1) for sums $A$ numbers from arithmetic progressions with different start numbers $K$ and end numbers $L$, multiplied on the number 4 .

Table 1. $A=(K+\ldots+L) 4$

\begin{tabular}{|c|c|c|c|c|c|c|c|c|c|c|}
\hline & $\mathrm{L}=2$ & $\mathrm{~L}=3$ & $\mathrm{~L}=4$ & $\mathrm{~L}=5$ & $\mathrm{~L}=6$ & $\mathrm{~L}=7$ & $\mathrm{~L}=8$ & $\mathrm{~L}=9$ & $\mathrm{~L}=10$ & $\mathrm{~L}=11$ \\
\hline $\mathrm{K}=1$ & 12 & 24 & 40 & 60 & 84 & 112 & 144 & 180 & 220 & 264 \\
\hline $\mathrm{K}=2$ & 8 & 20 & 36 & 56 & 80 & 108 & 140 & 176 & 216 & 260 \\
\hline $\mathrm{K}=3$ & & 12 & 28 & 48 & 72 & 100 & 132 & 168 & 208 & 252 \\
\hline $\mathrm{K}=4$ & & & 16 & 36 & 60 & 88 & 120 & 156 & 196 & 240 \\
\hline $\mathrm{K}=5$ & & & & 20 & 44 & 72 & 104 & 140 & 180 & 224 \\
\hline $\mathrm{K}=6$ & & & & & 24 & 52 & 84 & 120 & 160 & 204 \\
\hline $\mathrm{K}=7$ & & & & & & 28 & 60 & 96 & 136 & 180 \\
\hline $\mathrm{K}=8$ & & & & & & & 32 & 68 & 108 & 152 \\
\hline $\mathrm{K}=9$ & & & & & & & & 36 & 76 & 120 \\
\hline $\mathrm{K}=10$ & & & & & & & & & 40 & 84 \\
\hline
\end{tabular}

We supposed together that every number $A$ from this table corresponds to some stable chemical element with $A$ number nucleons in nucleus, which the abundance is larger between close elements or its isotopes. At majority of cases it has place at really, except last row and some isolated elements. At these exceptional cases the number of nucleons in nucleus is different from the number in the table only on 1 or 2 (Table 2).

Table 2. Chemical elements with A nucleons in the nucleus

\begin{tabular}{|c|c|c|c|c|c|c|c|c|c|c|}
\hline & $\mathrm{L}=2$ & $\mathrm{~L}=3$ & $\mathrm{~L}=4$ & $\mathrm{~L}=5$ & $\mathrm{~L}=6$ & $\mathrm{~L}=7$ & $\mathrm{~L}=8$ & $\mathrm{~L}=9$ & $\mathrm{~L}=10$ & $\mathrm{~L}=11$ \\
\hline$K=1$ & $C_{6}^{12}$ & $M g_{12}^{24}$ & $C a_{20}^{40}$ & $N i_{28}^{60}$ & $K r_{30}^{84}$ & $C d_{48}^{112}$ & $N d_{60}^{144}$ & $\begin{array}{c}T a_{73}^{181} \\
-1 n\end{array}$ & $\begin{array}{l}R e_{86}^{222} \\
-2 n\end{array}$ & $\begin{array}{c}E O s_{108}^{265} \\
-1 n\end{array}$ \\
\hline$K=2$ & & $N e_{10}^{20}$ & $A r_{18}^{36}$ & $F e_{26}^{56}$ & $B r_{35}^{80}$ & $A r_{47}^{108}$ & $C e_{58}^{140}$ & $\begin{array}{c}L u_{71}^{175} \\
+1 n\end{array}$ & $\mathrm{Po}_{84}^{216}$ & $\begin{array}{l}E H f_{104}^{261} \\
\quad-1 n\end{array}$ \\
\hline$K=3$ & & $C_{6}^{12}$ & $S i_{14}^{28}$ & $T i_{22}^{48}$ & $G e_{32}^{72}$ & $\begin{array}{l}R u_{44}^{102} \\
-2 n\end{array}$ & $X e_{54}^{132}$ & $\begin{array}{c}T m_{69}^{169} \\
-1 n\end{array}$ & $\mathrm{~Pb}_{82}^{208}$ & $E s_{99}^{252}$ \\
\hline$K=4$ & & & $O_{8}^{16}$ & $A r_{18}^{36}$ & $N i_{28}^{60}$ & $S r_{38}^{88}$ & $S n_{50}^{120}$ & $C d_{64}^{156}$ & $P t_{78}^{196}$ & $P u_{94}^{240}$ \\
\hline $\mathrm{K}=5$ & & & & $N e_{10}^{20}$ & $C a_{20}^{44}$ & $G e_{32}^{72}$ & $\begin{array}{l}R h_{45}^{103} \\
+1 n \\
\end{array}$ & $C e_{58}^{140}$ & $H f_{72}^{180}$ & $R a_{88}^{224}$ \\
\hline $\mathrm{K}=6$ & & & & & $M g_{12}^{24}$ & $C r_{24}^{52}$ & $K r_{36}^{84}$ & $S n_{50}^{120}$ & $\begin{array}{c}T b_{65}^{159} \\
+1 n\end{array}$ & $\begin{array}{l}T l_{81}^{205} \\
-1 n\end{array}$ \\
\hline$K=7$ & & & & & & $S i_{14}^{28}$ & $N i_{28}^{60}$ & $M o_{42}^{96}$ & $\begin{array}{c}B a_{56}^{138} \\
-2 n\end{array}$ & $H f_{72}^{180}$ \\
\hline$K=8$ & & & & & & & $S_{16}^{32}$ & $Z n_{30}^{68}$ & $A g_{47}^{108}$ & $E u_{63}^{152}$ \\
\hline $\mathrm{K}=9$ & & & & & & & & $A r_{18}^{36}$ & $A s_{33}^{75}+! n$ & $S n_{50}^{120}$ \\
\hline $\mathrm{K}=10$ & & & & & & & & & $C a_{20}^{40}$ & $K r_{36}^{84}$ \\
\hline
\end{tabular}


The table shows how synthesis process was going and that for every number $m$ in the round bracket at (1) some complete shell corresponds. For example, we have in the third line the following sequence $C^{12}, S i^{28}, T i^{48}, G e^{72}, \ldots, P b^{208}$. Therefore the sequence of numbers in the round bracket in (1) is given by Nature.

The following question appears naturally: have two polyhedrons with same number of vertexes $4 \mathrm{~m}$ from (see Table 2) same combinatorial type, or are similar each other or congruent?

\section{COMBINATORIAL TYPE OF THE POLYHEDRONS}

The symmetry condition gives for us the possibility to construct combinatorial types of shell polyhedrons almost uniquely. We represent $\alpha$-particle as two triangles with common edge. Between planes of these triangles can be dihedral angel. Really, consider shell with $10 \alpha$-particles. As $10=5+5$, we can take $5 \alpha$ particles on one half sphere at vertexes of 5 regular polygon and other $5 \alpha$-particles on the second half sphere, see Figure, where we represent the sphere by stereographic projection on a plane. Then for the number $9=3+3+3$ we can take $3 \alpha$-particles along equator at the vertexes of equilateral triangle, $3 \alpha$ particles on the upper half sphere and $3 \alpha$-particles on the lower half sphere.

For the number $8=4+4$ we can take $4 \alpha$-particles on the upper half sphere and $4 \alpha$-particles on the lower half sphere using the vertexes of quadrates.

The shell with $7 \alpha$-particles is singular on our opinion. Unique symmetric position of $7 \alpha$-particles lies at vertexes of 7 regular polygon on the equator. But upper half sphere and lower half sphere will be almost empty. Therefore this shell will be weakly connect with the next shell. Probably therefore under division of $U^{235}$ the gap of the nucleus takes place on the shell with $7 \alpha$-particles.

At the case $6=3+3$ we can take two equilateral triangles on two half spheres by symmetric way. If the shell has $4 \alpha$-particles then the polyhedron has form on the Figure. The cases with 5 and 3 -particles are given at my article [7].

Another, but non symmetric way, gives the representation $7=5+1+1$. Then $5 \alpha$-particles lie on equator at vertexes of 5 regular polygon and $1 \alpha$-particle lies at North Pole and 1 one at the South Pole.
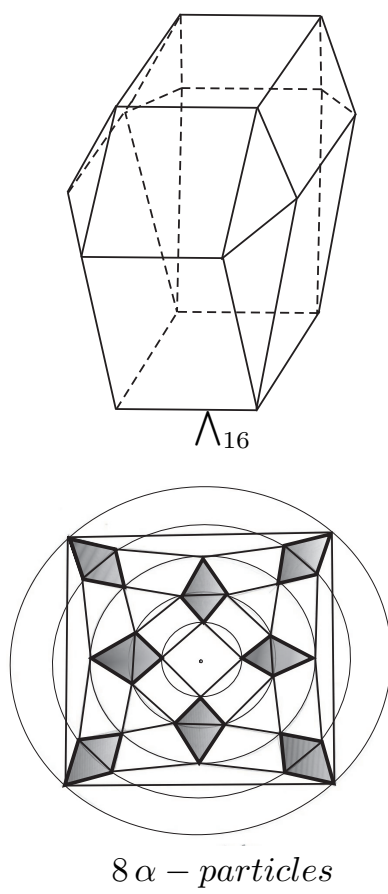
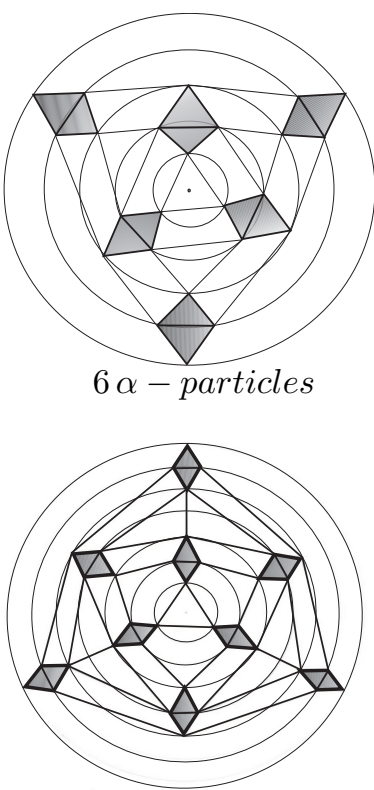

$9 \alpha-$ particles

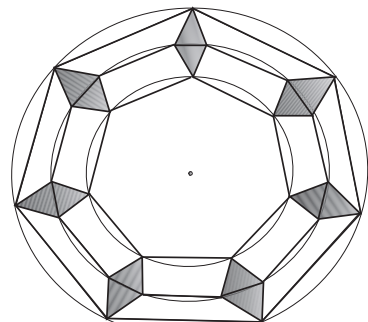

$7 \alpha$-particles

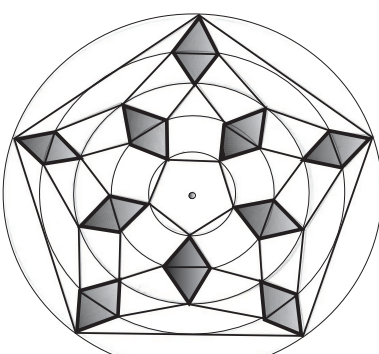

$10 \alpha-$ particles

Representation the sphere by stereographic projection on a plane

\section{References}

1. F.K. Valter, I.I.Zalubovsky. Nuclear Physics. Kharkiv, 1991.

2. M. Curie. Radioactivité. Paris, 1935.

3. E. Rezerford. Some cosmical aspects of radioactivity // J.Roy.Soc. Canada, Toronto, 1907, v.1, p.145-165.
4. Yu. Aminov. Polyhedrons at the nuclear structure // Problems of Atomic Science and Technology. Ser. "NPI". 2017, N3, p.21-25.

5. I.P. Selinov. Atomic nuclei and atomic transformations. GITTL, M.-L. 1951.

6. I.P.Selinov. The construction and system of atomic nuclei. M.: "Nauka", 1990. 


\section{ГЕОМЕТРИЧЕСКОЕ СТРОЕНИЕ ЯДЕР СВИНЦА И НЕКОТОРЫХ ДРУГИХ ХИМИЧЕСКИХ ЭЛЕМЕНТОВ}

\section{Ю. А. Аминов}

Внутренняя структура ядра химического элемента свинца дана в виде последовательности оболочек многогранников. Эта последовательность строится с помощью некоторой арифметической прогрессии положительных чисел, которая связана с гипотезой $\alpha$-частичного синтеза ядер. Другие химические элементы также рассмотрены с этой точки зрения. На графике распространенности химических элементов в Солнечной системе этим элементам соответствуют пики. В работе предложена таблица чисел нуклонов в ядрах этих элементов, а также соответствующая таблица элементов. Получен комбинаторный тип многогранных оболочек, входящих в состав ядер.

\section{ГЕОМЕТРИЧНА БУДОВА ЯДЕР СВИНЦЮ ТА ДЕЯКИХ ІНШИХ ХІМІЧНИХ ЕЛЕМЕНТІВ}

\section{Ю. А. Амінов}

Внутрішня будова ядра хімічного елемента свинцю представлена у вигляді послідовності оболонок у формі многогранників. Ця послідовність пов'язана з певною арифметичною прогресією додатних чисел, котра має відношення до гіпотези $\alpha$-часткового синтезу ядер. Інші хімічні елементи також розглянуті з цієї точки зору. На графіку поширення хімічних елементів у Сонячній системі цим елементам відповідають піки. У роботі запропонована таблиця чисел нуклонів в ядрах цих елементів, а також таблиця відповідних елементів. Отримано комбінаторний тип многогранних оболонок, які належать до складу ядер. 